\section{Potential kidney damage associated with the use of remdesivir for COVID-19: analysis of a pharmacovigilance database}

\author{
Potencial nefropatia associada ao uso do remdesivir \\ para COVID-19: análise de uma base de dados \\ de farmacovigilância
}

\begin{abstract}
Potenciales lesiones renales asociadas con el uso de remdesivir para la COVID-19: análisis de una base de datos de farmacovigilancia
\end{abstract}

\begin{abstract}
The U.S. Food and Drug Administration (FDA) has stated that the prescription of remdesivir should be cautious for patients with estimated glomerular filtration rate $(e G F R)<30$ and some studies reported risk of adverse renal events. The available information on the renal safety profile for remdesivir is limited, thus we analyzed the renal and urinary adverse reactions attributed to remdesivir reported in a large open pharmacovigilance database. We obtained reports of remdesivir and other drugs used to treat COVID-19 (tocilizumab, hydroxychloroquine, lopinavir/ritonavir) registered by September 30 2020, from the U.S. Food and Drug Administration Adverse Event Reporting System (FAERS). We analyzed the reporting odds ratios (RORs) for reports of adverse renal and urinary events for remdesivir and other drugs. We found 2,922 reports with remdesivir registered in FAERS for COVID-19. Among these, 493 renal and urinary adverse effects $(16.9 \%)$ were reported. The most frequent events were acute kidney injury (338; 11.6\%), renal impairment (86; 2.9\%), and renal failure $(53 ; 1.8 \%)$. Versus hydroxychloroquine, lopinavir/ritonavir, or tocilizumab, the use of remdesivir was associated with an increased chance of reporting renal and urinary disorders regardless of gender and age of patients (2.53; 95\%CI: 2.10-3.06). The ROR remained significant when we restricted the analysis to hydroxychloroquine (4.31; 95\%CI: 3.25-5.71) or tocilizumab (3.92; 95\%CI: 2.51-6.12). Our results reinforce this already reported signal, emphasizing that it could be extremely useful for health professionals who prescribe this new antiviral to treat COVID-19, mainly knowing its low efficacy.
\end{abstract}

Coronavirus Infections; Pharmacovigilance; Adverse Drug Reaction Reporting Systems; Drug-Related Side Effects and Adverse Reactions
Nayara Aparecida de Oliveira Silva 1 Ana Laura de Sene Amâncio Zara 2 Albert Figueras 3

Daniela Oliveira de Melo 1

doi: 10.1590/0102-311X00077721

\author{
Correspondence \\ D. O. Melo \\ Trav. Walter Bataglia 40, Diadema, SP 09913-030, Brasil. \\ melo.daniela@unifesp.br \\ 1 Universidade Federal de São Paulo, Diadema, Brasil. \\ 2 Instituto de Patologia Tropical e Saúde Pública, Universidade \\ Federal de Goiás, Goiânia, Brasil. \\ 3 Departament de Farmacologia, Universitat Autònoma de \\ Barcelona, Barcelona, España.
}




\section{Introduction}

Remdesivir received authorization for emergency use from the U.S. Food and Drug Administration (FDA), the European Medicines Agency (EMA) and the Brazilian Health Regulatory Agency (ANVISA) for treatment of severe coronavirus disease 2019 (COVID-19) 1,2,3. Although several countries have approved the emergency use of remdesivir, the World Health Organization (WHO) does not recommend the use of this drug for the treatment of COVID-19. According to a large, simple, international, open-label randomized trial conducted by the WHO, remdesivir, hydroxychloroquine, and lopinavir did not reduce the mortality, the need for mechanical ventilation, and the duration of hospitalization 4,5 . Despite the lack of efficacy, these drugs continue to be used in the treatment of COVID-19 in some countries, such as Brazil 6 .

In addition to efficacy, the safety of the drugs used to treat COVID-19 is a concerning aspect. The remdesivir formulation contains sulfobutylether-beta-cyclodextrin (SBECD) as an excipient, which accumulates in patients with kidney dysfunction 7,8 . In repeated dose toxicity studies in animals, dosedependent kidney injury and/or reduced function was detected with remdesivir, however this was not observed in the phase I clinical studies 9,10. Patients with an estimated glomerular filtration rate (eGFR) $<30$ were excluded from reported clinical trials of remdesivir 11, besides the FDA has stated that these patients should not receive remdesivir unless the potential benefit outweighs the potential risk 1 . Post-marketing retrospective studies have indicated that the use of remdesivir in patients with severe renal impairment is safe 12,13,14. On the other hand, a review of published studies describing the treatment with remdesivir 15 reported that four out of 53 patients with severe COVID-19 developed renal impairment 16 . Acute kidney injury (AKI) was also reported in two studies 16,17 . A recent analysis of 363 notification with remdesivir and COVID-19 from VigiBase (the pharmacovigilance system of the WHO) has suggested that remdesivir may cause acute renal failure 18.

The available information on the renal safety profile for remdesivir is still uncertain. Furthermore, concerning pharmacotherapy, COVID-19 itself may contribute to renal impairment. Between $20 \%$ and $40 \%$ of severe COVID-19 patients develop AKI and renal failure, mainly among those on mechanical ventilation due to a worse prognosis 19,20.

Thus, we designed a study to analyze the renal and urinary adverse reactions attributed to remdesivir reported in FDA Adverse Event Reporting System (FAERS) Public Dashboard (https://fis. fda.gov/sense/app/d10be6bb-494e-4cd2-82e4-0135608ddc13/sheet/7a47a261-d58b-4203-a8aa$6 \mathrm{~d} 3021737452 /$ state/analysis), a large open pharmacovigilance database, from almost 3,000 notifications with remdesivir used for COVID-19.

\section{Methods}

The FAERS Public Dashboard is an open access database that includes reports of suspected adverse drug reactions (ADR) coordinated by the FDA. The reports for remdesivir and other drugs used in the treatment of COVID-19 (tocilizumab, hydroxychloroquine, and lopinavir/ritonavir) received by FAERS in September 30, 2020, were identified and characterized. Only reports describing its use to treat "COVID-19", "Coronavirus Infection", or SARS-CoV-2 (severe acute respiratory syndrome coronavirus 2) were selected. The occurrence of renal adverse events belonging to the "Renal and Urinary Disorders" organ system of the Medical Dictionary for Regulatory Activities (MedDRA; https:// www.meddra.org/) was analyzed.

A disproportionality analysis was performed, and the reporting odds ratios (RORs) and corresponding 95\% confidence intervals (95\% CI) for the associations were calculated 21: (a) potential increased risk of reporting renal disorders with remdesivir compared with other drugs prescribed to treat COVID-19 (tocilizumab, hydroxychloroquine, and lopinavir/ritonavir), and (b) potential increased risk of reporting renal disorders with remdesivir versus other drugs. For these analyses, reports were excluded if more than one of the drugs analyzed was considered suspected of causing the adverse reaction. The ROR of a drug-ADR combination was defined as the ratio between proportions of reports containing the drug of interest in the "case" (reports containing the ADR of interest; renal 
events) and in the "non-case" (reports containing other ADRs) group. All analyses were performed using counts of unique cases. An association was considered statistically significant when the limit of the $95 \%$ CI was greater (lower limit) or lower (upper limit) than 1.0.

For analysis of renal adverse reactions considering the groups of drugs (hydroxychloroquine, lopinavir/ritonavir, and tocilizumab combined and independent), a univariate logistic regression was performed from the estimate of the ROR and its $95 \%$ CI. Gender and age variables were considered to calculate the adjusted ROR in the logistic regression model, performed by the stepwise method, excluding the missing cases, both for the group with remdesivir and the other groups (hydroxychloroquine, lopinavir, tocilizumab combined and independent). The 5\% significance level ( $\mathrm{p}<0.05)$ was considered for all statistical tests. The statistical analysis was conducted using the IBM SPSS Statistics program, version 25 (https://www.ibm.com/).

\section{Results}

We identified 2,922 notifications for remdesivir used to treat COVID-19. Almost all reports (2,859; $97.8 \%)$ originated in the United States, and most patients were male $(1,769 ; 60.5 \%)$ and $46 \%$ of the individuals were aged 65 years or older. In 2,747 reports (94\%), remdesivir was the only drug suspected of adverse events; in the remaining 128 reports, the suspected drugs were remdesivir and other drugs for COVID-19: hydroxychloroquine, tocilizumab, or lopinavir-ritonavir (90; 3.1\%), and other drugs unrelated to the treatment of COVID-19 (38; 1.3\%). Among the 2,922 reports analyzed, renal and urinary events were identified in 493 (16.9\%), and the most frequent events were AKI (338; $11.6 \%$ ), renal impairment ( $86 ; 2.9 \%)$, and renal failure (53; $1.8 \%)$.

Table 1 describes the number of adverse drug event reports associated with drugs used to treat COVID-19, when only one of the drugs was suspected of causing the adverse reaction. Lopinavir/ ritonavir and remdesivir are the drugs with the highest proportion of renal adverse events among patients with COVID-19. The comparison of remdesivir with other drugs for COVID-19 showed an increased chance of reporting renal and urinary disorders (ROR $=2.50$; 95\%CI: 2.11-2.95), AKI $(\mathrm{ROR}=2.77$; 95\%CI: 2.25-3.41), renal impairment $(\mathrm{ROR}=3.36$; 95\%CI: 2.15-5.24), and renal tubular necrosis $(\mathrm{ROR}=4.04 ; 95 \% \mathrm{CI}: 1.51-10.82)$ for remdesivir. The chance of reporting was even higher for almost all reactions comparing remdesivir with other drug for COVID-19, except lopinavir/ritonavir (Table 2).

Versus hydroxychloroquine, lopinavir/ritonavir, or tocilizumab, we associated the use of remdesivir with an increased chance of reporting renal and urinary disorders regardless of the patients' gender and age (adjusted ROR $=2.53$; 95\%CI: 2.10-3.06). The adjusted ROR of renal and urinary disorders regardless of patients' gender and age remained significant when we restricted the analysis to hydroxychloroquine (adjusted ROR $=4.31$; 95\%CI: 3.25-5.71) or tocilizumab (adjusted ROR $=3.92$; 95\%CI: 2.51-6.12) but not for lopinavir/ritonavir (adjusted ROR $=1.01$; 95\%CI: $0.78-1.30$ ) (Tables 3 and 4).

Table 1

Reports of adverse drug events associated with only one drug used to treat COVID-19. U.S. Food and Drug Administration Adverse Event Reporting System (FAERS), September 30, 2020.

\begin{tabular}{lccc}
\hline Drug & $\begin{array}{c}\text { Renal events } \\
{[\mathbf{n}=\mathbf{7 0 0}]} \\
\mathbf{n}(\mathbf{\%})\end{array}$ & $\begin{array}{c}\text { Non-renal events } \\
{[\mathbf{n = 5 , 1 4 1 ]}} \\
\mathbf{n}(\%)\end{array}$ & $\begin{array}{c}\text { Total } \\
{[\mathbf{n}=\mathbf{5 , 8 4 1 ]}} \\
\mathbf{n}(\mathbf{\%})\end{array}$ \\
\hline Remdesivir & $476(16.8)$ & $2,364(83.2)$ & $2,840(48.6)$ \\
Lopinavir/Ritonavir & $99(16.5)$ & $501(83.5)$ & $600(10.3)$ \\
Hydroxychloroquine & $94(5.4)$ & $1,645(94.6)$ & $1,739(29.8)$ \\
Tocilizumab & $31(4.7)$ & $631(95.3)$ & $662(11.3)$ \\
\hline
\end{tabular}


Table 2

Disproportionality analysis of reports of renal adverse drug reactions (ADR) in patients treated with remdesivir compared with other drugs for COVID-19. U.S. Food and Drug Administration Adverse Event Reporting System (FAERS), September 30, 2020.

\begin{tabular}{|c|c|c|c|c|c|}
\hline \multirow[t]{2}{*}{ Drug/ADR } & \multicolumn{2}{|c|}{ Remdesivir } & \multicolumn{2}{|c|}{ Comparator } & \multirow[t]{2}{*}{ ROR $(95 \% \mathrm{Cl})$} \\
\hline & With ADR * & No ADR ** & With ADR *** & No ADR \# & \\
\hline \multicolumn{6}{|c|}{$\begin{array}{l}\text { Remdesivir } x \text { hydroxychloroquine, lopinavir/ritonavir, and } \\
\text { tocilizumab }(n=5,841)\end{array}$} \\
\hline Renal and urinary disorders & $476(16.8)$ & $2,364(83.2)$ & $224(7.5)$ & $2,777(92.5)$ & $2.50(2.11-2.95)$ \\
\hline Acute kidney injury & $328(11.5)$ & $2,512(88.5)$ & $135(4.5)$ & $2,866(95.5)$ & $2.77(2.25-3.41)$ \\
\hline Renal impairment & $81(2.9)$ & $2,759(97.1)$ & $26(0.9)$ & $2,975(99.1)$ & $3.36(2.15-5.24)$ \\
\hline Renal failure & $51(1.8)$ & $2,789(98.2)$ & $36(1.2)$ & $2,965(98.8)$ & $1.51(0.98-2.32)$ \\
\hline Renal tubular necrosis & $19(0.7)$ & $2,821(99.3)$ & $5(0.2)$ & $2,996(99.8)$ & $4.04(1.51-10.82)$ \\
\hline Nephropathy toxic & $6(0.2)$ & $2,834(99.8)$ & $3(0.1)$ & $2,998(99.9)$ & $2.12(0.53-8.47)$ \\
\hline \multicolumn{6}{|c|}{ Remdesivir $\mathrm{x}$ tocilizumab $(\mathrm{n}=3,502)$} \\
\hline Renal and urinary disorders & $476(16.8)$ & $2,364(83.2)$ & $31(4.7)$ & $631(95.3)$ & $4.10(2.82-5.96)$ \\
\hline Acute kidney injury & $328(11.5)$ & $2,512(88.5)$ & $15(2.3)$ & $647(97.7)$ & $5.63(3.33-9.52)$ \\
\hline Renal impairment & $81(2.9)$ & $2,759(97.1)$ & $3(0.5)$ & $659(99.5)$ & $14.96(3.63-61.65)$ \\
\hline Renal failure & $51(1.8)$ & $2,789(98.2)$ & $6(0.9)$ & $656(99.1)$ & $2.00(0.85-4.68)$ \\
\hline Renal tubular necrosis & $19(0.7)$ & $2,821(99.3)$ & $0(0.0)$ & $662(100.0)$ & $\# \#$ \\
\hline Nephropathy toxic & $6(0.2)$ & $2,834(99.8)$ & $0(0.0)$ & $662(100.0)$ & $\# \#$ \\
\hline \multicolumn{6}{|c|}{ Remdesivir $\mathrm{x}$ hydroxychloroquine $(n=4,579)$} \\
\hline Renal and urinary disorders & $476(16.8)$ & $2,364(83.2)$ & $94(5.4)$ & $1,645(94.6)$ & $3.52(2.80-4.44)$ \\
\hline Acute kidney injury & $328(11.5)$ & $2,512(88.5)$ & $61(3.5)$ & $1,678(96.5)$ & $3.59(2.71-4.75)$ \\
\hline Renal impairment & $81(2.9)$ & $2,759(97.1)$ & $10(0.6)$ & $1,729(99.4)$ & $5.08(2.62-9.82)$ \\
\hline Renal failure & $51(1.8)$ & $2,789(98.2)$ & $5(0.3)$ & $1,734(99.7)$ & $6.34(2.53-15.92)$ \\
\hline Renal tubular necrosis & $19(0.7)$ & $2,821(99.3)$ & $3(0.2)$ & $1,736(99.8)$ & 3.89 (1.15-13.19) \\
\hline Nephropathy toxic & $6(0.2)$ & $2,834(99.8)$ & $1(0.1)$ & $1,738(99.9)$ & $3.68(0.44-30.59)$ \\
\hline \multicolumn{6}{|c|}{ Remdesivir x lopinavir/ritonavir $(n=3,440)$} \\
\hline Renal and urinary disorders & $476(16.8)$ & $2,364(83.2)$ & $99(16.5)$ & $501(83.5)$ & $1.02(0.80-1.29)$ \\
\hline Acute kidney injury & $328(11.5)$ & $2,512(88.5)$ & $59(9.8)$ & $541(90.2)$ & $1.20(0.89-1.60)$ \\
\hline Renal impairment & $81(2.9)$ & $2,759(97.1)$ & $13(2.2)$ & $587(97.8)$ & $1.33(0.73-2.40)$ \\
\hline Renal failure & $51(1.8)$ & $2,789(98.2)$ & $25(4.2)$ & $575(95.8)$ & $0.42(0.26-0.68)$ \\
\hline Renal tubular necrosis & $19(0.7)$ & $2,821(99.3)$ & $2(0.3)$ & $598(99.7)$ & $2.01(0.47-6.67)$ \\
\hline Nephropathy toxic & $6(0.2)$ & $2,834(99.8)$ & $2(0.3)$ & $598(99.7)$ & $0.63(0.13-3.14)$ \\
\hline
\end{tabular}

95\%Cl: 95\% confidence interval; ROR: reporting odds ratios.

Note: values in bold are statistically significant.

* Notifications received about the use of remdesivir for COVID-19 and adverse events of interest;

** Notifications received about the use of remdesivir for COVID-19 and without adverse events of interest;

$* * *$ Notifications received about the comparator drug due to use in COVID-19 and adverse events of interest;

\# Notifications received about the comparator drug due to use in COVID-19 and without adverse events of interest;

\#\# It was not possible to calculate due to the absence of notification on the use for COVID-19. 
Table 3

Disproportionality analysis of reports of renal and urinary disorders in patients treated with remdesivir compared with other drugs for COVID-19, per age group.

\begin{tabular}{|c|c|c|c|c|c|c|}
\hline \multirow[t]{2}{*}{ Drug/Age group (years) } & \multirow[t]{2}{*}{$\mathbf{n}$} & \multicolumn{2}{|c|}{ Remdesivir } & \multicolumn{2}{|c|}{ Comparator } & \multirow[t]{2}{*}{ ROR $(95 \% \mathrm{Cl})$} \\
\hline & & With ADR * & No ADR ** & With ADR *** & No ADR \# & \\
\hline \multicolumn{7}{|c|}{$\begin{array}{l}\text { Remdesivir } x \text { hydroxychloroquine, lopinavir/ritonavir, } \\
\text { and tocilizumab }(n=5,125)\end{array}$} \\
\hline $0-29$ & 444 & $14(8.3)$ & $154(91.7)$ & $11(4.0)$ & 265 (96.0) & $2.19(0.97-4.94)$ \\
\hline $30-39$ & 349 & $11(5.6)$ & $187(94.4)$ & $13(8.6)$ & $138(91.4)$ & $0.62(0.27-1.44)$ \\
\hline $40-49$ & 546 & 35 (11.3) & $276(88.7)$ & $6(2.6)$ & $229(97.4)$ & $4.84(2.00-11.71)$ \\
\hline $50-59$ & 889 & $78(17.2)$ & $375(82.8)$ & $33(7.6)$ & $403(92.4)$ & $2.54(1.65-3.91)$ \\
\hline $60-69$ & 1,234 & $149(22.3)$ & $518(77.7)$ & $42(7.4)$ & $525(92.6)$ & $3.60(2.50-5.17)$ \\
\hline $70-79$ & 1,064 & $121(20.5)$ & $469(79.5)$ & $51(10.8)$ & $423(89.2)$ & $2.14(1.50-3.05)$ \\
\hline $80-89$ & 516 & $50(15.1)$ & $281(84.9)$ & $16(8.6)$ & $169(91.4)$ & $1.88(1.04-3.41)$ \\
\hline$\geq 90$ & 83 & $10(17.5)$ & $47(82.5)$ & $0(0.0)$ & $26(100.0)$ & $\# \#$ \\
\hline \multicolumn{7}{|c|}{ Remdesivir $\mathrm{x}$ tocilizumab $(\mathrm{n}=3,243)$} \\
\hline $0-29$ & 200 & $14(8.3)$ & $154(91.7)$ & $1(3.1)$ & 31 (96.9) & $2.82(0.36-22.22)$ \\
\hline $30-39$ & 221 & $11(5.6)$ & $187(94.4)$ & $0(0.0)$ & $23(100.0)$ & $\# \#$ \\
\hline $40-49$ & 361 & $35(11.3)$ & $276(88.7)$ & $3(6.0)$ & $47(94.0)$ & $1.99(0.59-6.72)$ \\
\hline $50-59$ & 536 & $78(17.2)$ & $375(82.8)$ & $3(3.6)$ & $80(96.4)$ & $5.55(1.71-18.02)$ \\
\hline $60-69$ & 825 & $149(22.3)$ & $518(77.7)$ & $12(7.6)$ & $146(92.4)$ & $3.50(1.89-6.48)$ \\
\hline 70-79 & 680 & $121(20.5)$ & 469 (79.5) & $2(2.2)$ & $88(97.8)$ & $11.35(2.76-46.76)$ \\
\hline $80-89$ & 359 & $50(15.1)$ & $281(84.9)$ & $1(3.6)$ & $27(96.4)$ & $4.80(0.64-36.16)$ \\
\hline$\geq 90$ & 61 & $10(17.5)$ & $47(82.5)$ & $0(0.0)$ & $4(100.0)$ & $\# \#$ \\
\hline \multicolumn{7}{|c|}{ Remdesivir $x$ hydroxychloroquine $(n=4,128)$} \\
\hline $0-29$ & 353 & $14(8.3)$ & $154(91.7)$ & $7(3.8)$ & $178(96.2)$ & $2.31(0.91-5.87)$ \\
\hline 30-39 & 286 & $11(5.6)$ & $187(94.4)$ & $1(1.1)$ & $87(98.9)$ & $5.12(0.65-40.27)$ \\
\hline $40-49$ & 452 & $35(11.3)$ & $276(88.7)$ & $2(1.4)$ & $139(98.6)$ & $8.81(2.09-37.18)$ \\
\hline $50-59$ & 715 & $78(17.2)$ & $375(82.8)$ & $4(1.5)$ & $258(98.5)$ & $13.42(4.85-37.10)$ \\
\hline $60-69$ & 918 & $149(22.3)$ & $518(77.7)$ & $12(4.8)$ & $239(95.2)$ & $5.73(3.12-10.52)$ \\
\hline 70-79 & 869 & $121(20.5)$ & $469(79.5)$ & $22(7.9)$ & $257(92.1)$ & $3.01(1.87-4.87)$ \\
\hline $80-89$ & 457 & $50(15.1)$ & $281(84.9)$ & $11(8.7)$ & $115(91.3)$ & $1.86(0.94-3.70)$ \\
\hline$\geq 90$ & 78 & $10(17.5)$ & $47(82.5)$ & $0(0.0)$ & $21(100.0)$ & \#\# \\
\hline \multicolumn{7}{|c|}{ Remdesivir x lopinavir/ritonavir $(n=3,304)$} \\
\hline $0-29$ & 227 & $14(8.3)$ & $154(91.7)$ & $3(5.1)$ & $56(94.9)$ & $1.70(0.47-6.13)$ \\
\hline 30-39 & 238 & $11(5.6)$ & $187(94.4)$ & $12(30.0)$ & $28(70.0)$ & $0.14(0.06-0.34)$ \\
\hline $40-49$ & 355 & $35(11.3)$ & $276(88.7)$ & $1(2.3)$ & $43(97.7)$ & $5.45(0.73-40.84)$ \\
\hline $50-59$ & 544 & $78(17.2)$ & $375(82.8)$ & $26(28.6)$ & $65(71.4)$ & $0.52(0.31-0.87)$ \\
\hline $60-69$ & 825 & $149(22.3)$ & $518(77.7)$ & $18(11.4)$ & $140(88.6)$ & $2.24(1.33-3.78)$ \\
\hline 70-79 & 695 & $121(20.5)$ & 469 (79.5) & $27(25.7)$ & $78(74.3)$ & $0.75(0.46-1.21)$ \\
\hline $80-89$ & 362 & $50(15.1)$ & 281 (84.9) & $4(12.9)$ & 27 (87.1) & $1.20(0.40-3.58)$ \\
\hline$\geq 90$ & 58 & $10(17.5)$ & $47(82.5)$ & $0(0.0)$ & $1(100.0)$ & $\# \#$ \\
\hline
\end{tabular}

95\%Cl: 95\% confidence interval; ADR: adverse drug reactions; ROR: reporting odds ratios.

Note: values in bold are statistically significant.

* Notifications received about the use of remdesivir for COVID-19 and adverse events of interest;

** Notifications received about the use of remdesivir for COVID-19 and without adverse events of interest;

*** Notifications received about the comparator drug due to use in COVID-19 and adverse events of interest;

\# Notifications received about the comparator drug due to use in COVID-19 and without adverse events of interest;

\#\# It was not possible to calculate due to the absence of notification on the use for COVID-19. 
Table 4

Disproportionality analysis of reports of renal and urinary disorders in patients treated with remdesivir compared with other drugs for COVID-19, per age group - crude and adjusted - on September 30, 2020.

\begin{tabular}{|c|c|c|}
\hline Drug/Age group (years) & Crude ROR $(95 \% \mathrm{Cl})$ & Adjusted ROR $(95 \% \mathrm{Cl})$ \\
\hline \multirow{2}{*}{\multicolumn{3}{|c|}{$\begin{array}{l}\text { Remdesivir } \mathrm{x} \text { hydroxychloroquine, } \\
\text { lopinavir/ritonavir, and tocilizumab }\end{array}$}} \\
\hline & & \\
\hline Remdesivir & $2.50(2.11-2.95)$ & $2.53(2.10-3.06)$ \\
\hline $0-29$ & $2.19(0.97-4.94)$ & $0.56(0.26-1.22)$ \\
\hline $30-39$ & $0.62(0.27-1.44)$ & $0.58(0.27-1.28)$ \\
\hline $40-49$ & $4.84(2.00-11.71)$ & $0.63(0.30-1.33)$ \\
\hline $50-59$ & $2.54(1.65-3.91)$ & $1.15(0.57-2.30)$ \\
\hline $60-69$ & $3.60(2.50-5.17)$ & $1.47(0.74-2.91)$ \\
\hline $70-79$ & $2.14(1.50-3.05)$ & $1.54(0.78-3.10)$ \\
\hline $80-89$ & $1.88(1.04-3.41)$ & $1.09(0.54-2.24)$ \\
\hline Female & $2.93(2.07-4.15)$ & $0.84(0.70-1.01)$ \\
\hline \multicolumn{3}{|l|}{ Remdesivir $x$ tocilizumab } \\
\hline Remdesivir & $4.10(2.82-5.96)$ & $3.92(2.51-6.12)$ \\
\hline $0-29$ & $2.82(0.36-22.22)$ & $0.45(0.19-1.05)$ \\
\hline $30-39$ & * & $0.27(0.11-0.68)$ \\
\hline $40-49$ & $1.99(0.59-6.72)$ & $0.63(0.30-1.35)$ \\
\hline $50-59$ & $5.55(1.71-18.02)$ & $0.97(0.47-1.99)$ \\
\hline $60-69$ & $3.50(1.89-6.48)$ & $1.36(0.67-2.75)$ \\
\hline $70-79$ & $11.35(2.76-46.76)$ & $1.18(0.58-2.40)$ \\
\hline $80-89$ & $4.80(0.64-36.16)$ & $0.84(0.40-1.77)$ \\
\hline Female & $3.46(1.50-7.98)$ & $0.88(0.72-1.09)$ \\
\hline \multicolumn{3}{|c|}{ Remdesivir $\mathrm{x}$ hydroxychloroquine } \\
\hline Remdesivir & $3.52(2.80-4.44)$ & $4.31(3.25-5.71)$ \\
\hline $0-29$ & $1.70(0.47-6.13)$ & $0.56(0.25-1.25)$ \\
\hline $30-39$ & $0.14(0.06-0.34)$ & $0.30(0.12-0.72)$ \\
\hline $40-49$ & $5.45(0.73-40.84)$ & $0.61(0.29-1.29)$ \\
\hline $50-59$ & $0.52(0.31-0.87)$ & $0.94(0.46-1.92)$ \\
\hline $60-69$ & $2.24(1.33-3.78)$ & $1.39(0.70-2.80)$ \\
\hline $70-79$ & $0.75(0.46-1.21)$ & $1.38(0.69-2.78)$ \\
\hline $80-89$ & $1.20(0.40-3.58)$ & $1.04(0.50-2.14)$ \\
\hline Female & $5.49(3.20-9.43)$ & $0.83(0.68-1.01)$ \\
\hline \multicolumn{3}{|c|}{ Remdesivir x lopinavir/ritonavir } \\
\hline Remdesivir & $1.02(0.80-1.29)$ & $1.01(0.78-1.30)$ \\
\hline $0-29$ & $1.70(0.47-6.13)$ & $0.38(0.17-0.89)$ \\
\hline $30-39$ & $0.14(0.06-0.34)$ & $0.51(0.23-1.14)$ \\
\hline $40-49$ & $5.45(0.73-40.84)$ & $0.53(0.25-1.13)$ \\
\hline $50-59$ & $0.52(0.31-0.87)$ & $1.08(0.53-2.21)$ \\
\hline $60-69$ & $2.24(1.33-3.78)$ & $1.16(0.57-2.35)$ \\
\hline $70-79$ & $0.75(0.46-1.21)$ & $1.26(0.62-2.56)$ \\
\hline $80-89$ & $1.20(0.40-3.58)$ & $0.83(0.39-1.73)$ \\
\hline Female & $1.13(0.70-1.80)$ & $0.85(0.70-1.04)$ \\
\hline
\end{tabular}

95\% Cl: 95\% confidence interval; ROR: reporting odds ratios.

Note: values in bold are statistically significant.

* It was not possible to calculate due to the absence of notification on the use for COVID-19. 


\section{Discussion}

The evidence about the safety profile of remdesivir used to treat COVID-19 in clinical settings is still uncertain. Thus, we searched in a large pharmacovigilance database, such as FAERS, to quickly identify signals confirmed with observational studies and a recent analysis of VigiBase indicated a higher highest risk of acute renal failure in patients with COVID-19 treated with remdesivir compared to tocilizumab, lopinavir/ritonavir and hydroxychloroquine $(\mathrm{ROR}=20.3$; 95\%CI: 15.7-26.3) 18 . The FAERS analysis in this study and the VigiBase analysis conducted by Gérard et al. 18 showed the increased chance of reporting renal disorders of different severity regardless of gender and age, even in a conservative analysis of the data, including only reports of adverse drug events associated with only one drug used to treat COVID-19. Thus, the FAERS result contributes to the strengthening of the renal disorder signal in patients with COVID-19 using remdesivir previously identified in VigiBase.

Kidney damage could be one of the consequences of the infection with SARS-CoV-2 and the immunological cascade prompted by the virus. It could also be a consequence of these patients' comorbidities associated with COVID-19, by any means, the high proportion of renal and urinary reactions reported for patients using remdesivir are remarkable. Therefore, it generates a hypothesis to be confirmed in future studies and alerts health professionals to be aware of the potential nephrotoxic effect of remdesivir.

Renal adverse events may likely be associated with other nephrotoxic drugs used during the treatment of COVID-19, however in almost all reported cases, remdesivir was the only suspected drug and no other characteristic of the patients explained the observed difference. Despite the limitations of the disproportionality analyses of pharmacovigilance database reports, this method is well-known for identify unknown or poorly known adverse drug reactions, especially to new medicines or medicines used in situations different from those previously studied (signals). In fact, the EMA recently detected a safety signal about the use of remdesivir and the occurrence of kidney injury. The causal association has not yet been established and is under investigation 22 .

Spontaneous reporting systems (SRS), such as FAERS, are important to detect signals in the post-marketing surveillance, however SRSs have important limitations arising with underreporting, incomplete reporting, and duplicate reporting ${ }^{23}$. The sub-notification can overestimate the risk of an event with false-positive results. The quality of the report depends on the notifier's ability to recognize a possible association between medication use and the development of ADR. The event may sometimes be related to the patient's clinical condition (pre-existing diseases) or other medication not identified by the notifier as suspicious. Another recurring problem in the reports is the lack of information or the provision of incorrect information about the patient's characteristics (sex and age), comorbidities, and concomitant drugs that compromise the data analysis. There may also be notification of a similar incident by different reports (e.g., event notified by both the patient and by the physician), thus increasing the false positive rate 24 . Besides the limitations inherent in the SRSs themselves, we also observed limitations related to the study design. The interference of pre-existing comorbidities in the disproportionality analysis was not evaluated.

The signals identified with the SRS do not reflect the real incidence of ADR, since we found no information about exposure of the general population to the drug 23,25. The signal has an exploratory character that serves as a starting point to emphasize early potential security problems and to instigate additional studies on these possible questions 26 .

\section{Conclusion}

Our findings emphasize the relevance of the EMA's alert and stressed the analysis of this suspected safety concern, especially if the ongoing clinical trials recommend the use of remdesivir to treat COVID-19. Including a much larger number of notifications, our analysis reinforces the signal identified in VigiBase in a previous study. Thus, even though we found limitations, the analysis of the notifications allows us to infer the need of monitoring the renal function during remdesivir treatment, particularly in patients with risk factors (such as advanced age), pre-existing renal impairment or those receiving combination therapy with nephrotoxic drugs. 


\section{Contributors}

All authors contributed to the study design, data analysis and interpretation, writing, and critical review of the article.

\section{Additional informations}

ORCID: Nayara Aparecida de Oliveira Silva (00000003-3019-2851); Ana Laura de Sene Amâncio Zara (0000-0001-7012-9078); Albert Figueras (0000-0002-2740-2013); Daniela Oliveira de Melo (0000-0001-8613-7953).

\section{Acknowledgments}

We thank Adalton Guimarães Ribeiro and Alfredo José Alves Rodrigues Neto for comments that greatly improved the manuscript and statistical analysis, respectively.

\section{References}

1. U.S. Food and Drug Administration. Coronavirus (COVID-19) update: FDA issues emergency use authorization for potential COVID-19 treatment. https://www.fda.gov/ news-events/press-announcements/corona virus-covid-19-update-fda-issues-emergencyuse-authorization-potential-covid-19-treat ment (accessed on 11/Oct/2020).

2. European Medicines Agency. First COVID-19 treatment recommended for EU authorisation. https://www.ema.europa.eu/en/news/ first-covid-19-treatment-recommended-euauthorisation (accessed on 11/Oct/2020).

3. Agência Nacional de Vigilância Sanitária. Anvisa aprova registro da vacina da Fiocruz/ AstraZeneca e de medicamento contra o coronavírus. https://www.gov.br/anvisa/pt-br/ assuntos/noticias-anvisa/2021/anvisa-apro va-registro-da-vacina-da-fiocruz-astrazene ca-e-de-medicamento-contra-o-coronavirus (accessed on 04/Jun/2021).

4. Rochwerg B, Siemieniuk RA, Agoritsas T, Lamontagne F, Askie L, Lytvyn L, et al. A living WHO guideline on drugs for covid-19. BMJ 2020; 370:m3379.

5. WHO Solidarity Trial Consortium. Repurposed antiviral drugs for Covid-19 - Interim WHO Solidarity Trial Results. N Engl J Med 2021; 384:497-511.

6. Santos-Pinto CDB, Miranda ES, Osorio-deCastro CGS. "Kit-covid" and the Popular Pharmacy Program in Brazil. Cad Saúde Pública 2021; 37:e00348020.

7. Luke DR, Tomaszewski K, Damle B, Schlamm HT. Review of the basic and clinical pharmacology of sulfobutylether- $\beta$ - cyclodextrin (SBECD). J Pharm Sci 2010; 99:3291-301.

8. Hoover RK, Alcorn H, Lawrence L, Paulson SK, Quintas M, Luke DR, et al. Clinical pharmacokinetics of sulfobutylether- $\beta$-cyclodextrin in patients with varying degrees of renal impairment. J Clin Pharmacol 2018; 58:814-22.

9. Fisher M, Neugarten J, Bellin E, Yunes M, Stahl L, Johns TS, et al. AKI in hospitalized patients with and without COVID-19: a comparison study. J Am Soc Nephrol 2020; 31:2145-57.

10. European Medicines Agency. Summary on compassionate use: Remdesivir Gilead. https://www.ema.europa.eu/en/documents/ other/summary-compassionate-use-remdesi vir-gilead_en.pdf (accessed on 11/Oct/2020).

11. Adamsick ML, Gandhi RG, Bidell MR, Elshaboury RH, Bhattacharyya RP, Kim AY, et al. Remdesivir in patients with acute or chronic kidney disease and COVID-19. J Am Soc Nephrol 2020; 31:1384-6.

12. Thakare S, Gandhi C, Modi T, Bose S, Deb S, Saxena N, Katyal A, et al. Safety of remdesivir in patients with acute kidney injury or CKD. Kidney Int Rep 2021; 6:206-10. 
13. Pettit NN, Pisano J, Nguyen CT, Lew AK, Hazra A, Sherer R, et al. Remdesivir use in the setting of severe renal impairment: a theoretical concern or real risk? Clin Infect Dis 2020; [Online ahead of print].

14. Meshram HS, Kute VB, Patel H, Banerjee S, Navadiya V, Desai S, et al. Feasibility and safety of remdesivir in SARS-CoV2 infected renal transplant recipients: a retrospective cohort from a developing nation. Transpl Infect Dis 2021; 23:e13629.

15. Fan Q, Zhang B, Ma J, Zhang S. Safety profile of the antiviral drug remdesivir: an update. Biomed Pharmacother 2020; 130:110532.

16. Grein J, Ohmagari N, Shin D, Diaz G, Asperges E, Castagna A, et al. Compassionate use of remdesivir for patients with severe Covid-19. N Engl J Med 2020; 382:2327-36.

17. Wang Y, Zhang D, Du G, Du R, Zhao J, Jin $A$, et al. Remdesivir in adults with severe COVID-19: a randomised, double-blind, placebo-controlled, multicentre trial. Lancet 2020; 395:1569-78.

18. Gérard AO, Laurain A, Fresse A, Parassol N, Muzzone M, Rocher F, et al. Remdesivir and acute renal failure: a potential safety signal from disproportionality analysis of the WHO safety database. Clin Pharmacol Ther 2021; 109:1021-4.

19. Hirsch JS, Ng JH, Ross DW, Sharma P, Shah $\mathrm{HH}$, Barnett RL, et al. Acute kidney injury in patients hospitalized with COVID-19. Kidney Int 2020; 98:209-18.
20. Gabarre P, Dumas G, Dupont T, Darmon M, Azoulay E, Zafrani L. Acute kidney injury in critically ill patients with COVID-19. Intensive Care Med 2020; 46:1339-48.

21. Faillie JL. Case-non-case studies: principle, methods, bias and interpretation. Therapie 2019; 74:225-32.

22. European Medicines Agency. Meeting highlights from the Pharmacovigilance Risk Assessment Committee (PRAC) 28 September - 1 October 2020. https://www.ema.europa. eu/en/news/meeting-highlights-pharmaco vigilance-risk-assessment-committee-prac28-september-1-october-2020 (accessed on 11/Oct/2020).

23. Ventola CL. Big data and pharmacovigilance: data mining for adverse drug events and interactions. P T 2018; 43:340-51.

24. Hazell L, Shakir SAW. Determinants of underreporting of adverse drug reactions: a systematic review. Drug Saf 2006; 29:385-96.

25. Duggirala HJ, Tonning JM, Smith E, Bright RA, Baker JD, Ball R, et al. Use of data mining at the Food and Drug Administration. J Am Med Inform Assoc 2016; 23:428-34.

26. Coloma PM, Trifirò G, Patadia V, Sturkenboom M. Postmarketing safety surveillance: where does signal detection using electronic healthcare records fit into the big picture? Drug Saf 2013; 36:183-97. 


\section{Resumo}

De acordo com a Agência de Controle de Alimentos e Medicamentos dos Estados Unidos (FDA), a prescrição do remdesivir deve ser feita com cautela em pacientes com taxa de filtração glomerular estimada $(T F G e)<30$, sendo que diversos estudos relatam risco de eventos adversos renais. São limitados os dados disponíveis sobre o perfil de segurança renal do remdesivir. Assim, analisamos as reações adversas renais e urinárias atribuidas ao remdesivir e notificadas em um grande base de dados abertos de farmacovigilância. Obtivemos notificações sobre remdesivir e outros medicamentos usados para tratar a COVID-19 (tocilizumabe, hidroxicloroquina, lopinavir/ritonavir) registradas até 30 de setembro de 2020 do Sistema de Notificação de Eventos Adversos da FDA (FAERS). Analisamos as razões de chances de notificação (RORs) para notificações de eventos adversos renais e urinários referentes ao remdesivir e outros medicamentos. Encontramos 2.922 notificações sobre remdesivir registradas no FAERS para COVID-19. Entre esses casos, foram notificados 493 efeitos adversos renais e urinários $(16,9 \%)$. Os eventos mais frequentes foram lesão renal aguda (338; 11,6\%), comprometimento renal (86; 2,9\%) e insuficiência renal $(53 ; 1,8 \%)$. Comparado com a hidroxicloroquina, lopinavir/ritonavir ou tocilizumabe, o uso do remdesivir esteve associado com um aumento das chances de notificação de transtornos renais e urinários, independentemente do sexo e idade dos pacientes (2,53; IC95\%: 2,10-3,06). A ROR permaneceu significativo quando limitamos a análise à hidroxicloroquina (4,31; IC95\%: 3,25-5,71) ou ao tocilizumabe (3,92; IC95\%: 2,51-6,12). Nossos resultados corroboram outros estudos e destacam a utilidade para profissionais da saúde que usam esse novo antiviral para tratar a COVID-19, sobretudo em função de sua baixa eficácia.

Infecções por Coronavírus; Farmacovigilância; Sistemas de Notificação de Reações Adversas a Medicamentos; Efeitos Colaterais e Reações Adversas Relacionados a Medicamentos

\section{Resumen}

La Agencia Americana de Control de Alimentos $y$ Medicamentos (FDA) ha destacado que la prescripción de remdesivir debe ser prudente con pacientes con tasa de filtración glomerular estimada $(\mathrm{TGFe})<30$; además, algunos estudios informaron del riesgo de reacciones adversas renales. La información disponible sobre el perfil de seguridad renal, en el caso del remdesivir, es limitada. Por ello, analizamos las reacciones adversas renales y urinarias atribuidas al remdesivir e notificadas en una extensa base de datos abierta de farmacovigilancia. Obtuvimos las notificaciones de remdesiviry otros medicamentos usados para tratar la COVID-19 (tocilizumab, hidroxicloroquina, lopinavir/ritonavir) registrados el 30 de septiembre de 2020 por el Sistema de Notificación de Eventos Adversos de la FDA (FAERS). Analizamos las odds ratios informadas (RORs) en el caso de informes de eventos adversos renales y urinarios adversos relacionados con el remdesivir y otros medicamentos. En el FAERS, encontramos 2.922 notificaciones de remdesivir registradas como medicament sospechoso usado en COVID-19. De estos, habian 493 con efectos renales y urinarios adversos (16,9\%). Los efectos adversos más frecuentes fueron lesiones renales agudas (338; 11,6\%), insuficiencia renal (86; 2,9\%), y fallo renal (53; 1,8\%). Frente a hidroxicloroquina, lopinavir/ritonavir, o tocilizumab, el uso de remdesivir se asoció con un riesgo mayor de notificar alteraciones renales $y$ urinarios, independientemente del género y edad de los pacientes (2,53; IC95\%: 2,10-3,06). La ROR permaneció significativo al restringir el análisis a la hidroxicloroquina (4,31; IC95\%: 3,25-5,71) o tocilizumab (3,92; IC95\%: 2,51-6,12). Nuestros resultados corroboran datos previos, algo que podría ser extremadamente útil para los profesionales de la salud que decidan usar este nuevo antiviral para tratar la COVID-19, sobre todo conociendo su baja eficacia.

Infecciones por Coronavirus; Farmacovigilancia; Sistemas de Registro de Reacción Adversa a Medicamentos; Efectos Colaterales y Reacciones Adversas Relacionados con Medicamentos
Submitted on 23/Mar/2021

Final version resubmitted on 18/Jun/2021

Approved on 02/Jul/2021 